\title{
Theodoro Peckolt: a produção científica de um pioneiro da fitoquímica no Brasil *
}

\author{
Theodoro Peckolt: the scientific work of a pioneer in \\ phytochemistry in Brazil
}

Nadja Paraense dos Santos

Pesquisadora do Laboratório de Modelagem Molecular Departamento de Química Orgânica - Instituto de Química/UFRJ Rua Tonelero, 68/604 22030-000 Rio de Janeiro RJ - Brasil nadja@iq.ufrj.br
SANTOS, N. P. dos.: Theodoro Peckolt: a produção científica de um pioneiro da fitoquímica no Brasil. História, Ciências, Saúde - Manguinhos, v. 12 , n. 2, p. 515-33, maio-ago. 2005.

Este trabalho descreve, analisa e avalia a produção científica de Theodoro Peckolt, naturalista e farmacêutico alemão, e sua contribuição decisiva para o desenvolvimento da fitoquímica no Brasil. Suas realizações são discutidas tendo como pano de fundo o meio cultural e científico do século XIX, compondo o seu legado e influência nas ciências brasileiras.

PALAVRAS-CHAVE: história da química no Brasil; Theodoro Peckolt; fitoquímica; farmácia.

SANTOS, N. P. dos. Theodoro Peckolt: The Scientific Work of a Pioneer in Phytochemistry in Brazil. História, Ciências, Saúde-Manguinhos, v. 12, n. 2, p. 515-33, May-Aug. 2005.

The article describes, analyzes, and evaluates the scientific production of Theodoro Peckolt, a German naturalist and pharmacist who made a decisive contribution to the development of phytochemistry in Brazil. His achievements are discussed against the backdrop of the nineteenthcentury cultural and scientific milieu, revealing his legacy and influence in the Brazilian sciences.

KEYWORDS: history of chemistry in Brazil; Theodoro Peckolt; phytochemistry; pharmacy. 


\section{Peckolt: uma aventura científica no Brasil}

$\mathrm{T}$ heodoro Peckolt (1822-1912) (Figura 1), farmacêutico alemão, chegou ao Brasil em novembro de 1847 e aqui permaneceu os 65 anos restantes de sua vida, legando-nos uma obra de cento e setenta publicações, entre artigos em periódicos e livros, com dados de suas análises de cerca de seis mil plantas, segundo nos informam Ihering (1912) e Mendonça (1912), em sua grande maioria pertencentes ao domínio da Mata Atlântica.

Em nossas pesquisas conseguimos identificar cerca de duas mil plantas, a respeito das quais Peckolt publicou dados de morfologia e botânica, e usos farmacêuticos ou alimentares. No entanto, ele apresentou análises químicas de apenas cerca de 285 plantas. Na grande maioria dos casos, ele analisava folhas, flores e cascas separadamente, e cada análise publicada correspondia a uma média de três ensaios realizados.

Filho de um capitão de lanceiros do Kaiser, as constantes transferências de seu pai obrigaram-no a completar sua formação em farmácia em várias cidades alemãs. Em 1843, prestou serviço militar como farmacêutico na fortaleza de Glogau (Peckolt, 1995). Estudou farmácia, posteriormente, nas Universidades de Rostock e Göttingen e, em 1846, por recomendação do dr. Reichenbach, começou a trabalhar no Jardim Botânico de Hamburgo (Mendonça, 1912). Reconhecendo as aptidões de Peckolt, Karl Friedrich Philipp von Martius (1794-1868) e August Wilhelm Eichler (1839-1887, botânico) o induziram a visitar o Brasil na excursão científica de 1847, a fim de estudar a flora tropical e remeter-lhes o material colecionado (Santos et al., 1998).

O caráter das relações entre a Alemanha e o Brasil modificou-se a partir do século XIX, tanto pela abertura dos portos quanto pela vinda da Arquiduquesa Leopoldina para casar-se com o futuro imperador dom Pedro I. Da corte da futura imperatriz vieram dois pintores e oito cientistas, entre eles von Martius, um dos principais incentivadores da vinda de Theodoro Peckolt para o Brasil. Essa geração era estimulada não só pelos relatos de Alexander von Humboldt (1769-1859), como também pelo fato de a partir de 1808 lhe haver sido franqueado um imenso território até então interditado, numa terra que apresentava possibilidades ilimitadas para a iniciativa intelectual e econômica. Inicia-se a época de ouro das pesquisas alemãs no Brasil (Fouquet, 1974).

No caso específico da imigração de jovens cientistas alemães para o Brasil no século XIX, além do interesse do governo, e também de esforços isolados de pessoas e instituições, devem-se acrescentar "as dificuldades do mercado de trabalho para jovens professores alemães naquele país, dada a tradicional rigidez do sistema universitário germânico" (Mangrich, 1991). 
Acreditamos que Peckolt pode ser inserido nessa explicação. Sua vinda para o Brasil foi influenciada tanto por von Martius como por outros cientistas alemães, que reconheciam sua capacidade de trabalho e, com certeza, vislumbraram que aqui ele teria maiores possibilidades em virtude do campo ampliado de atuação.

Após um curto período de permanência na cidade do Rio de Janeiro, onde trabalhou na farmácia de Simão Marcolino Fragoso, localizada na rua do Fogo (atual rua dos Andradas), número 75, Peckolt aprendeu a falar um português sofrível e conseguiu juntar o dinheiro necessário para comprar um animal de sela e fazer os arranjos de viagem para fora da corte.

Em setembro, Peckolt começou sua exploração do país. Viajando a cavalo, percorreu as províncias do Espírito Santo, Minas Gerais e Rio de Janeiro, estudando-lhes a flora. Recebeu pagamento de 50\$000 réis mensais para enviar plantas em herbário para Martius e sementes para os Jardins Botânicos de Berlim e Munique, assim como outros objetos de história natural. Em julho de 1851, foi aprovado no exame farmacêutico da Escola de Medicina do Rio de Janeiro.

Em novembro do mesmo ano, estabeleceu-se em Cantagalo (Rio de Janeiro), a convite de médicos e fazendeiros alemães e suíços lá instalados. Comprou uma farmácia e casou-se, em 12 de junho de 1854, com dona Henriqueta, filha do vigário protestante Friederich Sauerbrönn, da colônia suíça de Friburgo, cidade para a qual o pastor viera a fim de servir aos colonos.

Peckolt viveu entre Cantagalo e Friburgo durante 17 anos e, nesse período, adquiriu profundo conhecimento da flora e fauna local. Para dar continuidade a seus trabalhos de colaborador da Flora Brasiliensis, montou em sua farmácia um laboratório próprio (Figura 2) para realizar análises das plantas brasileiras. Peckolt permaneceu em Cantagalo até 1868 e ali realizou, segundo suas próprias declarações (Peckolt, 1911), cerca de quinhentas análises quantitativas de extratos de plantas da flora brasileira. Destas, 437 foram publicadas em revistas internacionais, entre 1850 e 1868.

Ele estudou plantas brasileiras de diversas famílias, observando as condições nas quais viviam e se multiplicavam, e recolheu dos nativos informações sobre nomes triviais, usos e propriedades farmacêuticas. O herbário fornecia-lhe os meios para a comparação morfológica das numerosas espécies e, no laboratório, Peckolt aprofundava o trabalho, obtendo informações detalhadas sobre a composição química das plantas medicinais, seus alcalóides e outras substâncias de extração. "Não conhecemos", diz Hermann von Ihering (1912), "outro exemplo de naturalista, versado igualmente em estudos botânicos e químicos, que tão profundamente tivesse estudado e esclarecido por investigações próprias o estudo econômico, farmacêutico e químico de qualquer flora tropical". 
No período de 1852 a 1867, ainda residente em Cantagalo, recebeu muitas honrarias acadêmicas, sendo nomeado membro correspondente da Real Sociedade Botânica de Regensburg (1852) e da Real Sociedade Farmacêutica da Alemanha (1857). Foi feito doutor honoris causa da Academia Cesárea Leopoldino-Carolino-Germânica, da Alemanha, em 1864, por seus numerosos trabalhos químicos e botânicos sobre a flora brasileira. Nesse mesmo ano, foi nomeado oficial da Ordem da Rosa, por sua participação na Exposição Nacional do Rio de Janeiro (1861), e, mais tarde, oficial da Estrela Polar do Rei da Suécia (1869).

Ao retornar ao Rio de Janeiro, Peckolt associou-se a Frederico Augusto Duvel, farmacêutico já estabelecido na corte, na farmácia Peckolt \& Duvel - Farmacêuticos da Casa Imperial, localizada na rua Direita número 59 (posteriormente, rua Primeiro de Março). Conforme informação disponível no Almanaque de 1867, tratava-se de "laboratório químico e farmacêutico pelo sistema alemão".

Em 1872, estabeleceu-se em farmácia de sua propriedade, a Pharmacia Imperial, na rua da Quitanda, 193, posteriormente 157 "em frente ao Beco do Bragança", que, segundo o anúncio publicado na seção de notabilidades do mesmo almanaque, seria a "Drogaria e Laboratorio de Productos Chimicos de T. Peckolt \& C." (Figura 3), onde já estavam alguns dos produtos que haviam sido apresentados por Peckolt nas exposições nacionais $(1861,1866)$ e universais $(1862,1867)$ : pós de doliarina, preparação de leite da gameleira, agoniadina fluida, extratos de caroba, salsaparrilha e japecanga (Figura 4). Na farmácia mandou construir um laboratório em que continuou a analisar nossas plantas.

Encontramos em 1872 o registro de Peckolt como membro adjunto da seção médica da Academia Imperial de Medicina. O nome de Peckolt aparece como membro titular da seção farmacêutica nos Annaes da Academia de Medicina do Rio de Janeiro, a partir de 1884, quando ocorre uma mudança nos estatutos. Entre 1896 e 1897 aparece como membro titular da seção de farmacologia e, a partir de 1900, como membro honorário da referida Academia.

Peckolt também foi membro da seção de química e toxicologia do Instituto Pharmaceutico do Rio de Janeiro (1858-1887), uma das mais importantes associações que congregou farmacêuticos no século XIX, e que, ao contrário de suas congêneres, teve vida longa, durando mais de trinta anos. Em 1884, essa entidade se ofereceu para instalar uma Escola de Farmácia no Rio de Janeiro, cujo lema era "educação dos farmacêuticos, pelos farmacêuticos", numa declarada tentativa de separar o curso de farmácia do ensino de medicina. Theodoro Peckolt era apresentado como professor do laboratório de química orgânica, biologia e toxicologia, tendo como substituto seu filho Gustavo Peckolt. Até o ano de 1889, encontramos registros da referida escola no Almanak Laemmert, embora San- 
tos Filho (1991) informe que a referida escola tivesse sido fechada por imposição da congregação da Faculdade de Medicina em 1866.

Em 1874, Peckolt foi contratado por Ladislau de Souza Mello e Netto (1838-1894), então diretor do Museu Nacional, para organizar a seção de química analítica, sendo responsável pelo laboratório químico. Esse cargo ocupado por Peckolt tem sido muito citado pelos historiadores da química no Brasil (Rheinboldt, 1955; Gonçalves, 1993; Mathias, 1995) como prodigioso em trabalhos, pois, "independente de suas ocupações normais, publicou numerosos trabalhos sobre zoologia, botânica, fitoquímica e entomologia nas principais revistas da Europa, da América do Norte e do Brasil" (Rheinboldt, 1955). A afirmação, todavia, não é confirmada pela documentação.

Em nossas pesquisas, realizadas junto ao Projeto Memória do Museu Nacional, conseguimos localizar alguns poucos documentos para tentar traçar o trabalho de Theodoro Peckolt à frente do Laboratório Químico do Museu Nacional. Conforme já destacamos, vários historiadores relatam esse período como um dos mais produtivos de Peckolt. Andrade (1949) chega a dizer: "Peckolt iniciou aí seus memoráveis trabalhos sobre as nossas plantas e as nossas coisas...". Todavia, Peckolt ficou à frente do laboratório por um período inferior a dois anos - de abril de 1874 a janeiro de 1876, saindo antes da reforma do museu, quando, por sinal, incorporou-se o laboratório a uma das seções, perdendo sua autonomia.

A leitura dos relatórios, documentos e ofícios do Museu Nacional nos faz inferir que o Laboratório Químico entrou em decadência nos últimos anos da gestão de Burlamaque e, principalmente, durante a gestão do botânico Francisco Freire Alemão (1866-1874), o primeiro a quebrar uma longa dinastia de diretores ligados diretamente à mineralogia ou à química. Concomitantemente, ocorreu a retirada de equipamentos e materiais pelas instituições de ensino da corte.

Ladislau Netto, no Relatório de 1874, diz, na parte referente ao laboratório, que

o antigo e outrora tão bem organizado laboratório do Museu Nacional ... faz de fogo morto há mais de 12 anos e ficará totalmente dentro de pouco tempo se não for desde já reformado e convenientemente elevado à altura em que exige a marcha progressiva das ciências físicas e naturais. Sobre estes reparos e melhoramentos pedi não há muito a V. Ex. autorização para que dele possa encarregar desde já o Sr. Theodoro Peckolt, ficando aquele ilustrado químico incumbido ao mesmo tempo das análises constantemente exigidas em boa parte de nossos trabalhos cotidianos. 
Encontramos um ofício do Ministério dos Negócios da Agricultura, Comércio e Obras Públicas, de março de 1874, solicitando a Ladislau Netto que indicasse a quantia necessária para o restabelecimento do Laboratório Químico e também a retribuição a ser dada a Peckolt (Museu Nacional, 1874, p. 24).

Peckolt iniciou seus trabalhos em maio de 1874 (Figura 5) com a aquisição de drogas e materiais da Alemanha (Dresden e Hamburgo) e nacionais (Museu Nacional, 1874). Segundo Ladislau Netto, no Relatório de 1875, quase nada pôde ser aproveitado do antigo laboratório, mas Peckolt estava montando um "laboratório moderno e preparado para quaisquer análises". Parte do terraço em construção seria destinado ao referido laboratório. Infelizmente, a biblioteca do Museu Nacional não possui o Relatório de 1876, que poderia nos ajudar a compreender a saída de Peckolt e a razão pela qual o Laboratório Químico deixou de fazer parte da estrutura do Museu a partir de 1877.

Do ano de 1876, encontramos apenas dois documentos relativos ao Laboratório Químico: o ofício no qual Peckolt solicitava o seu desligamento dos quadros do museu e uma nota de venda ao museu de produtos químicos da Drogaria e Farmácia Peckolt (Museu Nacional, 1876). A leitura do ofício com o pedido de desligamento de Peckolt transmite a sensação de mágoa e até mesmo de um certo alívio em deixar a instituição:

Ofício de 10 de janeiro de 1876

Ilmo. Sr.

Com sumo prazer tenho a honra de declarar a V. Sa. que desde o dia primeiro deste mês, deixo de pertencer à classe dos empregados deste Museu, porque conforme as exigências de V. Sa. não me é possível continuar no emprego de chefe do Laboratório Químico e espero que tenha a bondade de mandar riscar meu nome da lista dos ditos empregados.

Deus guarde V. Sa.

Rio de Janeiro, 10 de janeiro de 1876

Ao Ilmo. Sr. Dr. Ladislau Netto - Diretor do Museu Nacional

Ass: Dr. Theodoro Peckolt

Ao refletirmos sobre a saída de Theodoro Peckolt do Museu Nacional, podemos inferir que ele não se adaptou em ser um funcionário do museu e em exercer funções que não se enquadravam em seu perfil de pesquisador. Peckolt era um especialista nos estudos da fitoquímica de plantas brasileiras, e entre suas atribuições como responsável pelo Laboratório Químico do Museu estava também a 
análise de diversos materiais, prioritariamente minerais, que não eram seu objeto de estudo (Santos, 2002).

Peckolt também aparece como membro da Associação Brasileira de Aclimação, fundada em 7 de maio de 1872. A principal proposta dessa sociedade era pesquisar a viabilidade da domesticação de plantas nativas. Só encontramos registro dessa associação até o ano de 1884. Como dado curioso, Peckolt foi presidente do Club Schubert, sociedade musical alemã, fundada em 20 de novembro de 1882, que funcionou na Rua do Passeio, 11.

Peckolt também foi membro da Sociedade Nacional de Agricultura, onde ocupava a cadeira de número 13, o que não pudemos confirmar oficialmente, pois o arquivo histórico dessa instituição foi destruído em um incêndio. A informação foi obtida pessoalmente de seus descendentes. Peckolt também tinha prestígio junto ao antigo Instituto Brasileiro do Café, que em homenagem póstuma ornou seu túmulo com um uma escultura em bronze que representava ramos de café (Peckolt, 1998). Lamentavelmente, essa escultura foi furtada de seu jazigo.

\section{As publicações de Peckolt}

Inegavelmente, é de Theodoro Peckolt o recorde brasileiro de análise química das plantas da flora nacional do século XIX, e acreditamos que essa marca permaneça imbatível ainda hoje.

Já residente no Brasil, Peckolt começou a publicar seus trabalhos antes mesmo de começar a escrever em português. Os primeiros saíram em revistas farmacêuticas alemãs e, pelo que conseguimos averiguar, parece que suas primeiras obras em nossa língua foram as explicações que acompanhavam as coleções enviadas às exposições nacionais de 1861 e 1866. As publicações internacionais surgem no período entre 1859 e 1911 . Os estudos de 1860 a 1899 compreendem as espécies da flora brasileira de maior interesse na Europa. A partir de 1899, o estudo das plantas medicinais brasileiras tornou-se a tônica de sua obra publicada fora do país.

No necrológio escrito por Ihering (1912), contabilizamos 124 referências de autoria de Peckolt, em nossas pesquisas conseguimos localizar 170 publicações, entre artigos em periódicos e livros, sendo 32 em português, três em inglês e as 135 restantes em alemão.

As publicações em alemão são as que concentram a maior parte de sua obra, cerca de 79\%, com destaque para as seguintes revistas: Archiv der Pharmacie. Zeitschrift des Allgemeinen Deutschen ApothekerVereins (Berlim), na qual publicou entre 1859 e 1865, Zeitschrift des Allgemeinen Oesterreichischen Apotheker (Viena), colaboração entre 1865 e 1896, e Berichte der Deutschen Pharmazeutischen Gesellschaft (Berlim), entre 1896 e 1911. 
Interessante notar que 42 dessas obras foram publicadas enquanto Peckolt ainda residia em Cantagalo e que, das 128 publicadas enquanto fixou residência no Rio de Janeiro, apenas duas são do período em que esteve à frente do Laboratório Químico do Museu Nacional (1874-1875). Este dado questiona alguns de seus biógrafos, que em geral citam aquele período como um dos mais férteis de sua carreira.

Destacam-se entre as suas obras nacionais: Análises da matéria médica brasileira, 108 páginas (1868), História das plantas alimentares e de gozo do Brasil, em cinco fascículos (1871 a 1884) e História das plantas medicinais e úteis do Brasil, em oito fascículos (1888 a 1914 póstuma), escrita em colaboração com seu filho, também farmacêutico, Gustavo Peckolt (1861-1923). Este trabalho contém a classificação botânica e descreve, por exemplo, as técnicas de cultura, as partes próprias para uso, a composição química, o emprego em diversas moléstias, as doses e os usos industriais de plantas brasileiras. Estas duas últimas obras são ainda hoje citadas em virtude de sua amplitude.

Vamos nos deter nos seus dois primeiros trabalhos conhecidos em nossa língua, e nas explicações que acompanhavam as coleções enviadas para as exposições nacionais de 1861 e 1866.

Na seção de manuscritos da Biblioteca Nacional encontramos as explicações detalhadas, escritas pelo próprio Peckolt, para sua coleção de 146 produtos de farmacognosia e química orgânica enviada à Exposição Nacional de 1861. Na explicação de sua coleção, Peckolt informava que diversas análises ali apresentadas já se achavam publicadas nos Archivos de Pharmacia da Allemanha do Norte e conclama a organização de uma Farmacopéia Brasileira "que nos indique os vegetais que já foram experimentados terapeuticamente e quimicamente e que podem suprir senão suplantar as drogas vindas de fora" (Peckolt, 1861). Foram escolhidos e remetidos para a Exposição de Londres (1862) 225 produtos químicos e farmacêuticos; desse grupo fazia parte a coleção de Theodoro Peckolt, que seria contemplada com a medalha de ouro no evento internacional. A coleção encontrava-se repartida em sete séries, assim discriminadas:

$1^{\text {a }}$ Série - as drogas simples vegetais, raízes e sementes. Apresenta 15 produtos. Entre os que terão continuidade de estudo por Peckolt podemos citar:

a) Sapucainha (Carpotroche brasiliensis Endl.) - óleo usado como inseticida, parasiticida e principalmente utilizado no combate à Lepra;

b) Urucum (Bixa orellana) - urucuína, provavelmente a bixina;

c) Agoniada (Plumeria lancifolia Muell. Arg.) - agoniadina, glicosídeo extraído da casca - antiasmático e purgativo; 
${ }^{1}$ Para Peckolt as gomatas seriam as gomas vegetais que poderiam substituir a goma arábica industrialmente.
2 Mais tarde também chamada por ele pelo nome popular de 'cravo-de-defunto'. d) Sangue de drago (Croton lechieri) - eritraemita, ácido eritraêmico, extraído da casca - usado para infecções bacterianas.

2ª Série - as painas: apresenta a descrição botânica de 14 espécies, extrai o ácido oxálico da barba de velho (Tillandsia usenoides).

$3^{\text {a }}$ Série - os amidos (amiláceas): 23 espécies. Segundo Peckolt o amido foi tirado das plantas frescas; em todos os casos ele apresenta os teores de amido e de substância seca. Da Taiuiá (Cayaponia tayuya ou Trianosperma ficfolia) extraiu a taiuína ou trianospermina, provavelmente a caiaponina.

$4^{\text {a }}$ Série - as resinas, gomas e tintas: 42 substâncias divididas em:

a) adstringentes (sucos condensados);

b) gomatas $^{1}$ (propriedade principalmente arabina);

c) gomas cassorinas;

d) gomas resinas;

e) resinas naturais;

f) leite;

g) substâncias tintas [sic];

h) resinas, produtos das análises;

Desta $4^{a}$ série podemos salientar:

a) Sangue de Becuiba (Myristica bicuhyba Schoot.) - ácido becuíbico, extraído do óleo, usado nas ulcerações de pele, feridas e reumatismo;

b) Angelim Amargosa (Tabebuia serratifolia Vahl.) - andirina, princípio extraído da casca - usada para tratar ulcerações de pele;

c) Gameleira Branca (Ficus doliaria) - doliarina, princípio sui generis - vermífugo, purgativo, depurativo do sangue e anti-sifilítico. Peckolt apresenta também a análise da seiva vegetal por ele denominada "leite vegetal": teores de açúcar, resina, cera etc.;

d) Cravo do Mato $^{2}$ (Tagetes sp.) - tagetina, cetona extraída do óleo usado como anti-helmíntico.

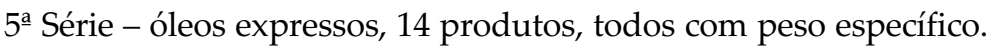

6 $6^{\text {a }}$ Série - preparações obtidas pela análise, num total de oito, algumas já citadas anteriormente.

$7^{\text {a }}$ Série - alguns óleos e éteres, total de 28, destacamos:

a) Cipó-suma (Anchietea salutaris A.St.Hil.) - anchietina, alcalóide. Desta planta ele apresenta também a análise da raiz. O cipó-suma era usado como purgativo e indicado para lesões sifilíticas; 
b) Jaborandi (Pilocarpus jaborandi) - jaborandina, extraída da raiz, usada como diurético e mastigada contra dores de dentes;

c) Bucha paulista (Luffa operculata) - saponina, mistura de glicosídeos, usada como purgativo.

Sobre a coleção de 1861, escreveu Frederico Leopoldo Cesar Burlamaque, relator do Júri: “O Júri achou esta coleção tão importante que conferiu uma medalha de ouro a seu autor, ainda que na verdade, ela ofereça maior interesse científico que industrial" (Brasil, 1862). Nesse mesmo relatório, Burlamaque analisou a situação da incipiente, ou quase inexistente indústria química no Brasil.

No segundo evento desse gênero realizado no Brasil, em 1866, Peckolt apresentou uma nova coleção, esta enviada integralmente à Exposição de Paris (1867). Contabilizando 221 objetos, Peckolt explicava que esse número poderia ter sido maior não fossem as dificuldades de realizar seu trabalho no interior (ainda residia em Cantagalo), e seu plano de não apresentar ao público as drogas indígenas sem a prévia análise química (Santos et al., 1999). Existia também a preocupação em acompanhar cada produto com o preço provável de sua comercialização e uma tentativa de chamar a atenção dos agricultores e industriais sobre uma série de produtos. Nesse trabalho privilegiava os óleos essenciais e suas pesquisas sobre os teores de cafeína em diversos vegetais. Dividia sua obra em (Peckolt, 1866):

1ª́rie: Drogas indígenas - 45

2a Série: Extratos, resinas, gomatas etc. - 15

$3^{\text {a }}$ Série: Óleos fixos, óleos essenciais, preparações químicas etc. - 161

Ao final, apresentava duas tabelas, a primeira com vegetais que forneceram óleo essencial, incluindo seu peso específico, a segunda com os teores de cafeína de outros vegetais por ele analisados.

$\mathrm{Na}$ análise dessa segunda coleção podemos destacar que, diferentemente da primeira, Peckolt iria preocupar-se em apresentar a análise completa dos diferentes vegetais analisados, e no caso dos óleos fixos apresentou seu peso específico e a quantidade de óleo extraído para cada dez quilos da erva fresca, acompanhados geralmente do preço por onça. Destacamos estes produtos:

3 Segundo Carrara, Meirelles (1996) poderia ser a crisarobina, extraída da araroba (Andira araroba). a) agoniadina, glicosídeo extraído da casca da agoniada ou quina-branca (Plumeria lancifolia Muell. Arg.);

b) anchietina; alcalóide extraído do cipó-suma (Anchietea salutaris A.St.Hil.);

c) andirina, provavelmente princípio extraído do gênero Andira; ${ }^{3}$ 
d) angelina, provavelmente ácido angélico (ácido cis-alfametilcrotônico), extraído da angélica (Angelica Archangelica Linn.), bem como acetato de angelim;

e) cafeína;

f) carobina, provavelmente extrato de caroba (Jacaranda braziliensis), bem como acetato de carobina;

g) doliarina, princípio sui generis do leite da gameleira-branca (Ficus doliaria), e seus derivados: azodoliarinato de amônio e ácido azodoliarínico;

h) eritremita, substância extraída da casca de sangue-dedrago (Croton lechieri) e seu derivado, ácido eritrêmico;

i) jaborandina ou pilocarpina;

j) pereirina;

k) pocentina, princípio extraído da Euphorbia pulcherrima;

1) saponina, mistura de glicosídeos, extraída da planta do gênero Saponaria;

m) tagetina ou tagetona, cetona extraída dos tagetes ou cravosde-defunto (Tagetes erecta);

n) taiuína ou trianospermina, provavelmente caiaponina, princípio extraído do taiuiá (Cayaponia tayuya ou Trianosperma glandulosa);

o) timboína, alcalóide extraído do timbó (Serjania fuscifolia Radlk);

p) urucuína, provavelmente bixina, extraída do urucum (Bixa orellana);

q) ácido becuíbico, provavelmente extraído do óleo de bicuíba (Myristica bicuhyba Schoot.) e seus derivados: becuibatos de sódio, de cobre e de chumbo;

r) ácido benzóico, extraído da planta por ele chamada de óleo vermelho (Myrospermum erytroxylum Allem.);

s) ácido butírico, extraído do óleo essencial do café;

t) ácido oxálico, extraído da Tillandsia usenoides (barba-de-velho);

u) ácidos tânicos, extraídos de diversas plantas; ácido lecitistânico, da sapucaia (Lecithys sp); ácido guaraná-tânico, da semente de guaraná (Paullínia cupana), ácido mate-tânico, do chá-mate (Ilex paraguariensis); ácido piromato-tânico; ácido tânico da casca do guaranhém; ácido becuibtânico;

v) outros ácidos: ácido apoláustico, extraído das folhas do café; ácidos extraídos da mandioca, do chá-da-índia, da folha de congonha e da semente do mamão;

w) produtos não identificados: ácido araucário; ácido naniotímico; ácido palicurio; ácido oleo-cafeico; ácido oleo-caróbico, ácido carpotróquico, ácido estereo-carpotróquico; anisospermina, chinopoidina, feuilina, feuilstearina, ictioctonina, jacutupina, manihotina, massarandubina, miroxilina e tombina. 
No relatório (1869), entre os vários elogios à coleção Peckolt, os jurados enfatizaram a memória descritiva apresentada juntamente com as substâncias preparadas, na qual Peckolt, além de listar os processos empregados e as análises químicas feitas, procurou também destacar os atributos e virtudes de cada uma das substâncias exibidas e os nomes trivial e científico do vegetal que as forneceu.

A leitura dos relatórios sobre as exposições nacionais e universais destaca a qualidade dos produtos químicos fabricados no país, mas também a falta de um ensino de química mais voltado para aplicações industriais, bem como do incentivo à implementação de indústrias no país. No caso específico da indústria farmacêutica, em continuidade com a tendência verificada já na primeira metade do século XIX, algumas boticas, agora denominadas farmácias e drogarias, foram progressivamente se transformando em laboratórios farmacêuticos, responsáveis pela produção de medicamentos usados em mais larga escala. A partir da década de 1860 observou-se um efetivo incremento na produção, sustentado em procedimentos técnico-científicos.

Pelo que pudemos verificar, Theodoro Peckolt trabalhou inicialmente sozinho e, posteriormente, com seu filho Gustavo Peckolt. Seu método de trabalho era minucioso, já que procurava fornecer, além de descrições botânicas, dados precisos de análises químicas. Algumas delas - especialmente as de cinzas - foram feitas em laboratórios de universidades alemãs.

Peckolt pode ser considerado um dos precursores da etnofarmacologia, por considerar importante a sistematização e o estudo das tradições populares do uso das plantas medicinais como estratégia para a investigação e comprovação de suas propriedades terapêuticas. Outro ponto que podemos destacar no trabalho de Peckolt é que ele dava para quase todas as plantas uma sinonímia botânica e popular abundante. Além disso, sempre que possível, ele incluía, também, a sinonímia indígena dos vegetais analisados.

O trabalho de Peckolt é singular quando comparado ao de outros farmacêuticos brasileiros do século XIX. Seus estudos foram dirigidos pelos moldes da farmacognosia européia, isto é, consistiam em sistematizar, agrupar e organizar, ainda que com lacunas de informações. Conforme ele próprio nos informa em seu livro História das plantas medicinais e úteis do Brasil (1888-1914), não realizava menos de três análises em cada parte da planta antes de publicar, demonstrando seu caráter minucioso e metódico. Outra característica que se pode notar no amplo leque de seus trabalhos é o fato de quase nunca se restringir a analisar apenas a parte da planta normalmente usada pelo povo.

$\mathrm{Na}$ Europa ou no Brasil, sempre se seguia a ordem alfabética para os nomes científicos das plantas ou dos princípios ativos encontrados em determinados grupos de plantas. Em sua primeira 
coletânea, História das plantas alimentares e de gozo do Brasil, Peckolt utilizou a ordem alfabética para os nomes vulgares das plantas, com o objetivo de atingir um público maior - no caso, os agricultores. Mas já na sua coletânea seguinte, História das plantas medicinais e úteis do Brasil, retornou aos nomes científicos. Este último procedimento foi utilizado em suas publicações alemãs, nas quais ele geralmente discorre sobre os gêneros e as famílias como grandes grupos, para depois tratar de cada espécie individualmente.

Em suas obras Peckolt fez anotações importantes sobre diversos assuntos: geografia, topografia, geologia, hidrografia, clima e solo dos estados brasileiros. Ele considerava o homem como o agente mais perigoso no grupo dos modificadores dos terrenos e já previa, assim como outros naturalistas brasileiros da época, a futura necessidade de recuperação do solo destruído pela prática da queimada. Outras situações analisadas quimicamente por Peckolt e que, ainda hoje, permanecem bastante atuais são os efeitos das queimadas no ar que respiramos e o conseqüente aumento da temperatura.

Segundo Mors (1997), Peckolt isolou um grande número de compostos cuja identificação só foi possível algum tempo depois, com o aperfeiçoamento dos métodos de análise.

Em 13 de julho de 1902, quando Peckolt completou oitenta anos, seu prestígio internacional era tal que recebeu como presente um álbum com 105 fotografias de professores e pesquisadores de várias nacionalidades, a maioria dos quais alemães, todas com dedicatórias e assinaturas autênticas (Figura 6).

Sentindo faltar-lhe as forças, Theodoro registrou em cartório a venda da Farmácia Peckolt para seu filho Gustavo em 28 de outubro de 1911. Encontramos registros de funcionamento da farmácia até 1914, isto é, dois anos após a morte do fundador.

É singular que os resultados obtidos por esse incansável cientista tivessem sido tão pouco conhecidos e apreciados no país que ele considerava como sua segunda pátria. Em seus escritos brasileiros Peckolt reafirmava constantemente a necessidade de uma farmacopéia brasileira, bem como de mais pesquisas, por parte de médicos e farmacêuticos nacionais, sobre a flora brasileira.

A longevidade do clã Peckolt, na farmácia e na análise de plantas medicinais brasileiras, pode ser comprovada através dos trabalhos de seu filho Gustavo Peckolt e posteriormente de seu neto Oswaldo Lazarini Peckolt. Este último trabalhou na revisão feita em 1936 da Farmacopéia brasileira, trabalho de Rodolpho Albino, farmacêutico natural de Cantagalo, que havia sido publicada quase dez anos antes (1928). Em 1942 essa comissão foi substituída, pois o interesse do período estava voltado para os medicamentos sintéticos e para a alopatia, e só em 1952 saiu a primeira publicação da segunda Farmacopéia brasileira. Nessa segunda farmacopéia, as 138 plantas que constavam da primeira reduziram-se a dez. Desta forma, 


\footnotetext{
* Este artigo é parte da tese de doutorado da autora, intitulada Theodoro Peckolt: naturalista $e$ farmacêutico do Brasil Imperial, defendida pela área interdisciplinar de História das Ciências e Epistemologia (Coppe/UFRJ), em dezembro de 2002.
}

podemos constatar que as cerca de três mil plantas estudadas pelos Peckolts foram relegadas ao quase total esquecimento no meio científico.

Ainda hoje no Brasil são raros os trabalhos de pesquisa associando antropologia e farmacologia. O descaso brasileiro abre caminho para a biopirataria, o roubo de plantas e animais, levando a patentes no exterior de remédios pelos quais os brasileiros terão de pagar caro. Conforme já nos dizia Peckolt em 1888:

Ao publicarmos o resultado dos nossos estudos, não é nosso intuito apresentar a última palavra sobre tudo o que se refere aos vegetais indígenas e exóticos aclimatados entre nós; mas unicamente fornecer um ponto de partida para trabalhos de maior fôlego, que tenham o poder de significar que os médicos e farmacêuticos brasileiros compreendam que não lhes é lícito conservar-se inativos, concorrendo, assim, para que continuem a ser feitas no estrangeiro a maior parte das investigações sobre a Flora Brasileira.

\section{REFERÊNCIAS BIBLIOGRÁFICAS}

Almanaque

1853-1889

Andrade, Alfredo de 1949

Carrara Júnior, Ernesto;

Meirelles, Helio 1996

Brasil 1862

Danusa, Mara 2001

Museu Nacional 1874

Museu Nacional 1876

Fouquet, Carlos 1974

Gonçalves, Ailton L. 1993

Ihering, Hermann von 1912

Mangrich, Antonio 1991
Almanak Administrativo, Mercantil e Industrial da Corte e Província do Rio de Janeiro. Rio de Janeiro: Eduardo \& Henrique Laemmert.

História do Laboratório Químico do Museu Nacional. Revista da Sociedade Brasileira de Química, v. XVIII, n. 1-4, p. 53-61.

A indústria química e o desenvolvimento do Brasil.

2 v. São Paulo: Metalivros.

Exposição Nacional de 1861. Relatório Geral.

Rio de Janeiro: Typographia do Diário do Rio de Janeiro.

www.histoeplmed.2x.com.br, acesso em 1.8.2001.

Documentos Museu Nacional.

1874. 24, 28, 63, 68, 70, 84, pasta 13 .

Documentos Museu Nacional. 1876. 3, 41, pasta 15 .

O imigrante alemão e seus descendentes no Brasil: 1808-1824-1874.

São Paulo: Instituto Hans Staden; São Leopoldo: Federação dos Centros Culturais. 25.7.1974.

Difusão da Química no Brasil.

Rio de Janeiro: Sobreondas.

Necrológio.

Revista do Museu Paulista, v. IX, p. 55-84.

Presença química na implantação e desenvolvimento de um projeto de colonização durante o II império. Da história de Blumenau - SC.

Química Nova, v. 14, n. 1, p. 68-70. 


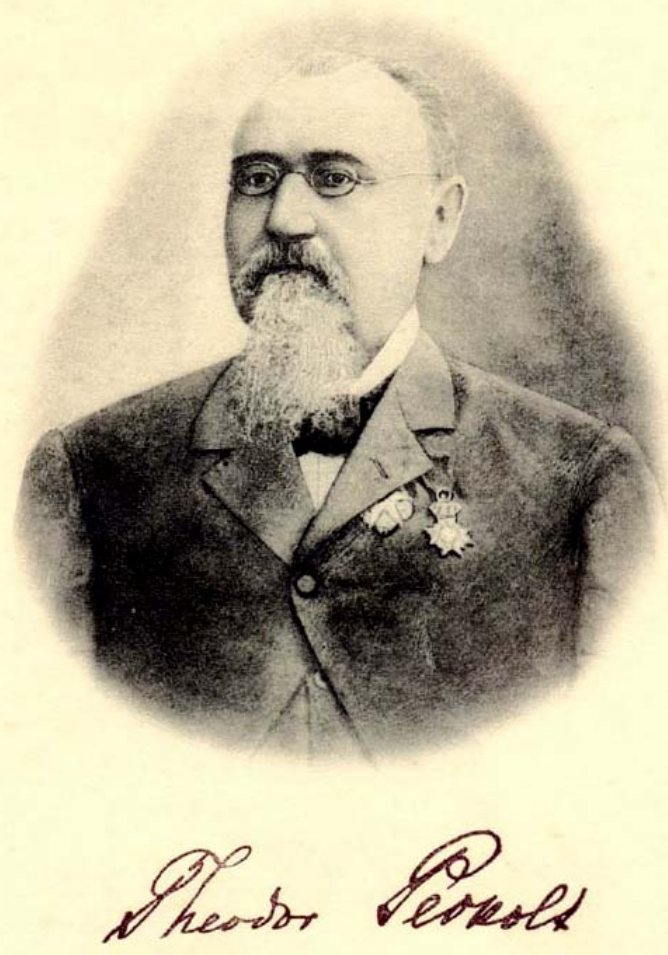

Figura 1 - Retrato de Theodoro Peckolt com assinatura (1822-1912) [Acervo Família Peckolt].

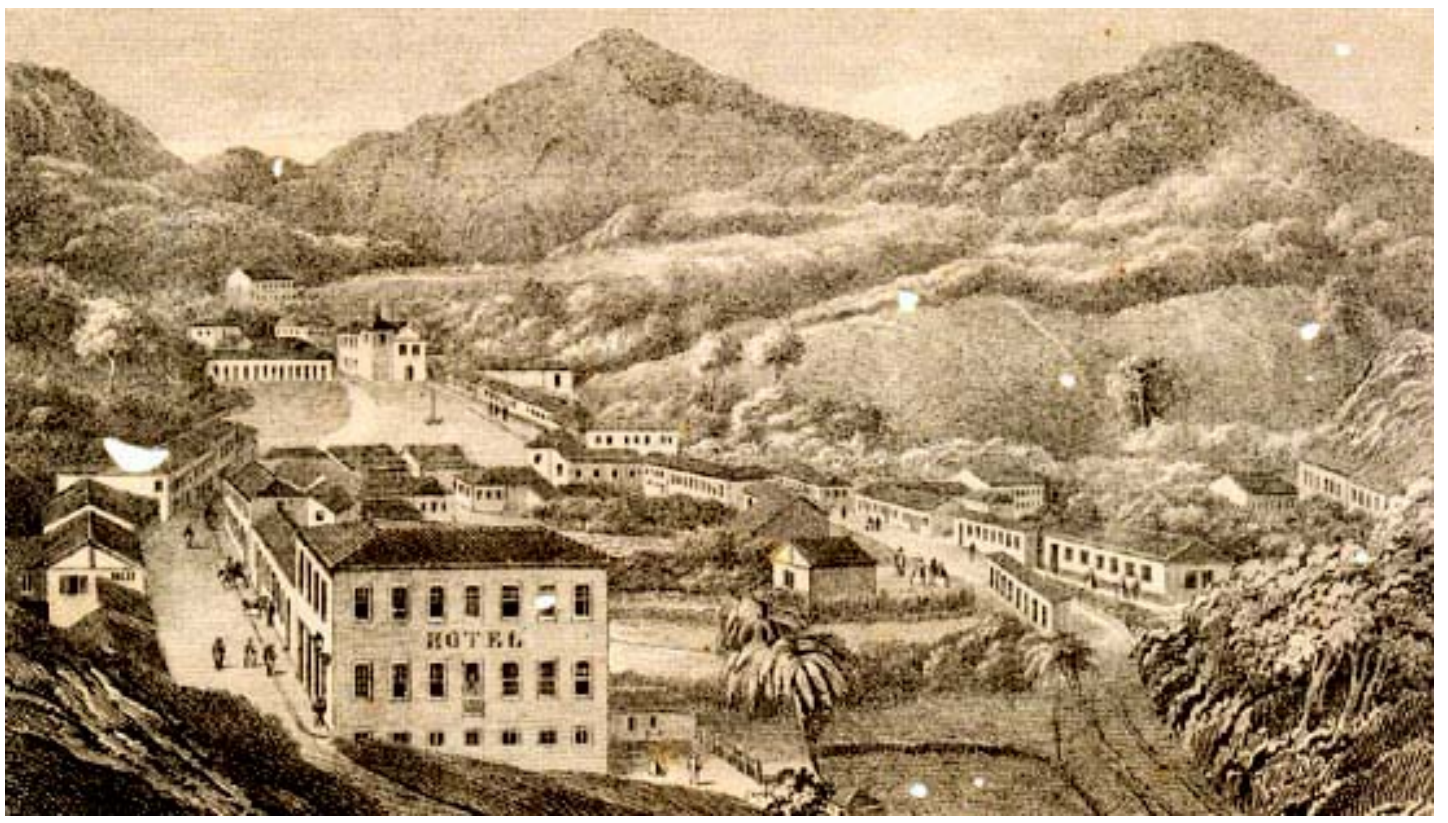

Figura 2 - Vista da cidade de Cantagalo (Rio de Janeiro) século XIX - Folha de rosto do bloco de notas da Farmácia Peckolt [Acervo Família Peckolt]. 

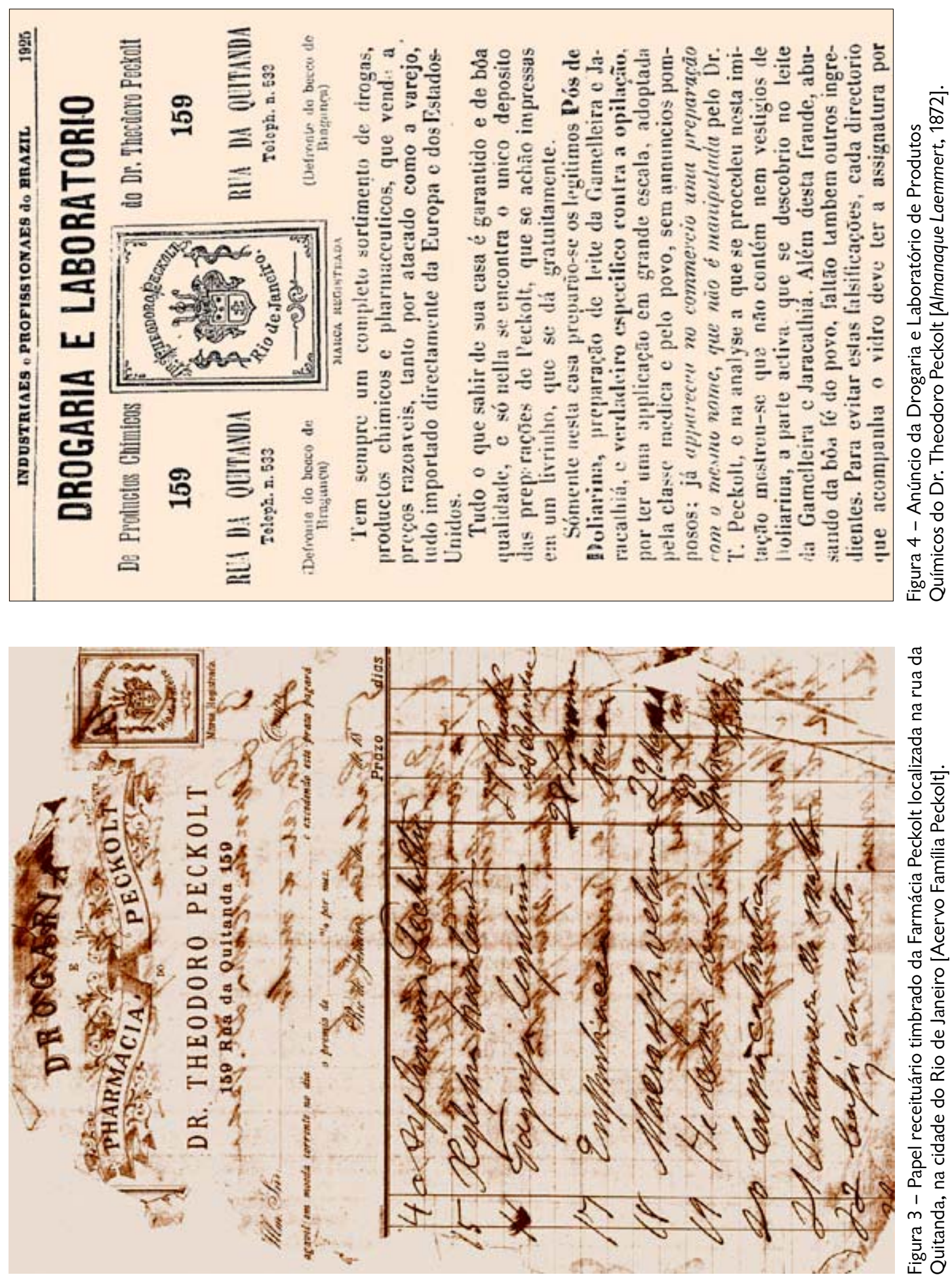


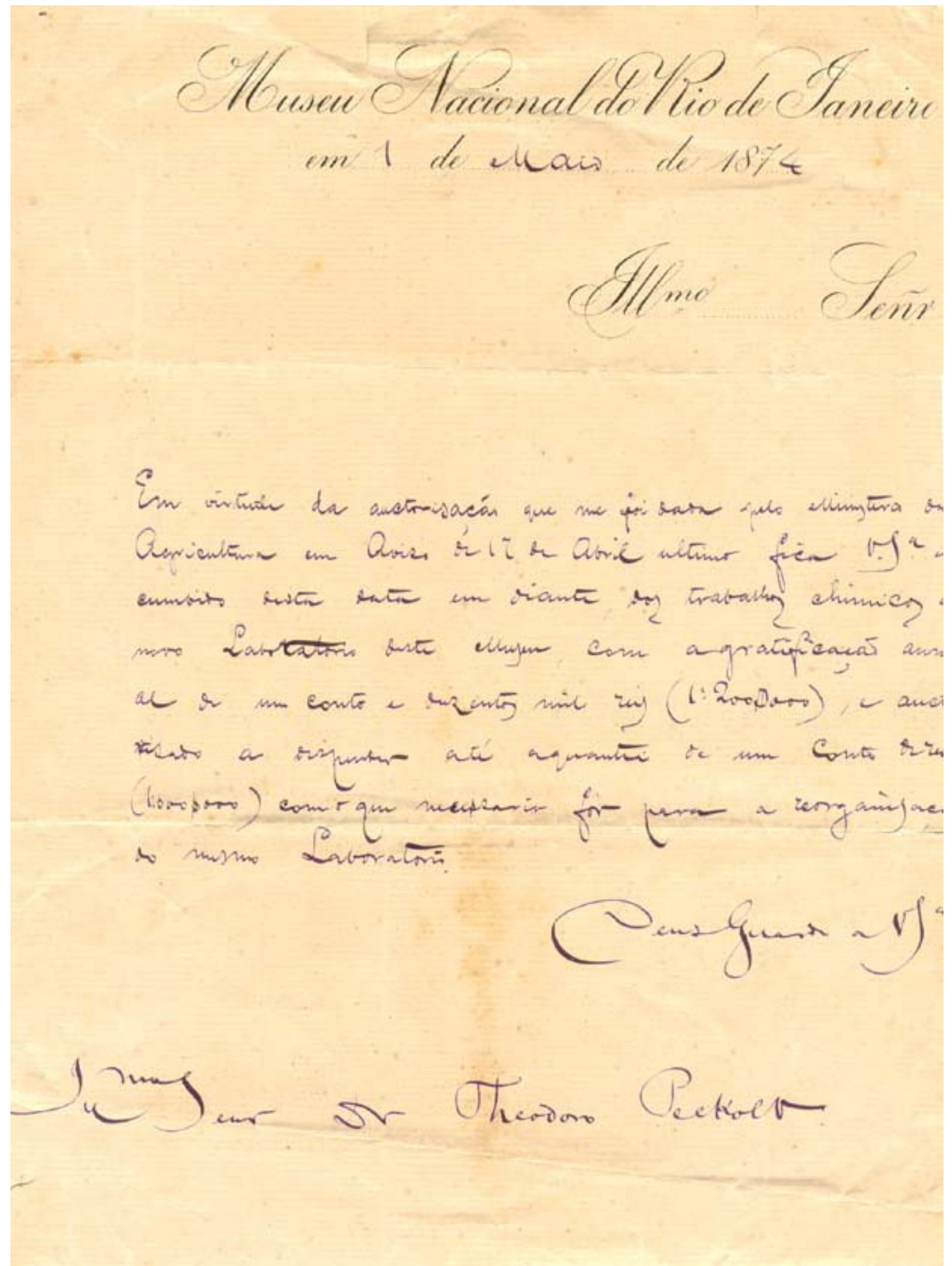

Figura 5 - Ofício de nomeação de Theodoro Peckolt como responsável pela reorganização do Laboratório Químico do Museu Nacional do Rio de Janeiro, 8 de maio de 1874 [Acervo Família Peckolt]. 


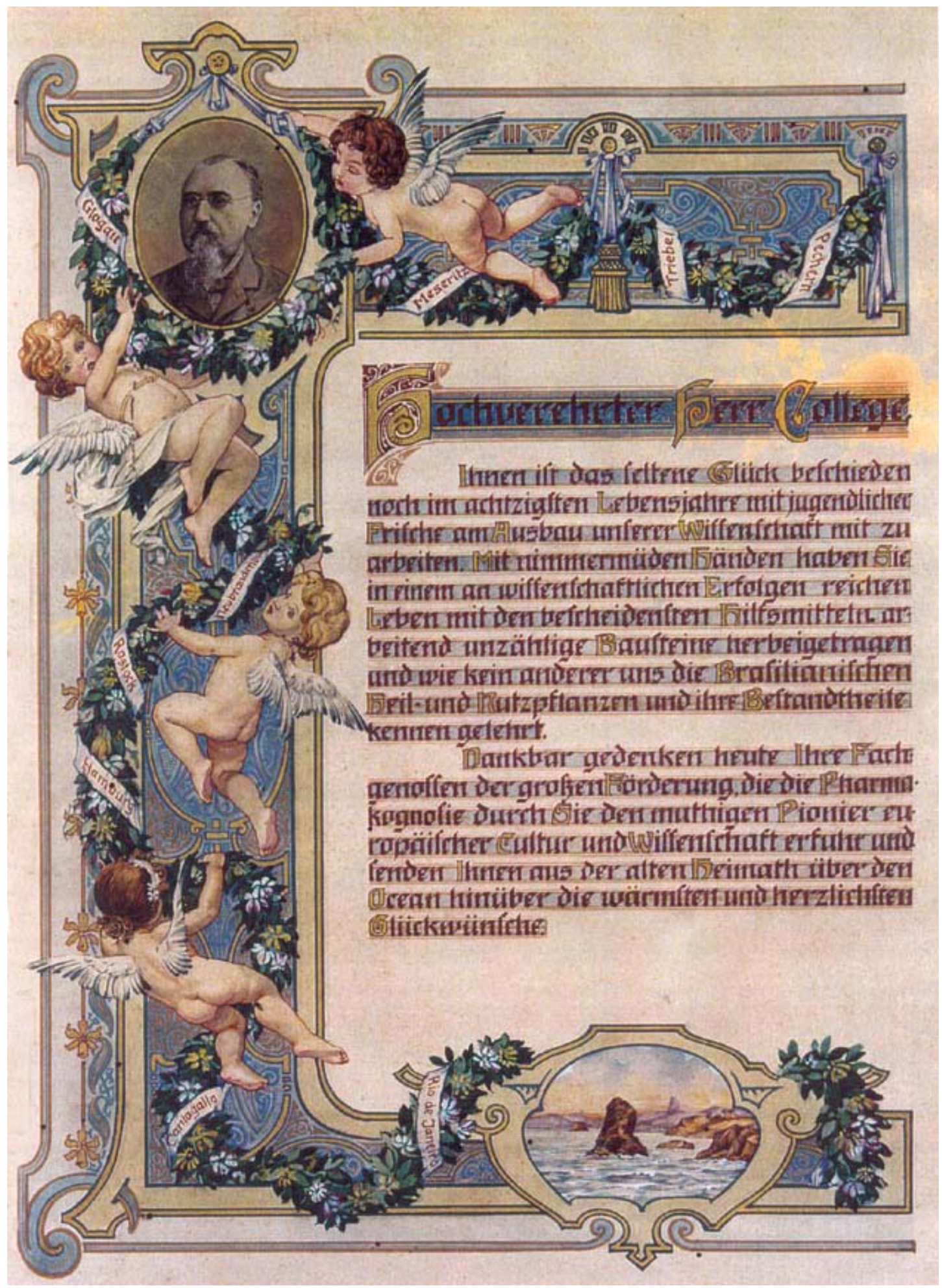

Figura 6 - Primeira página do livro de homenagens recebido por Peckolt na ocasião de seu 80ำ aniversário (13 de julho de 1912) [Acervo Família Peckolt]. 
Mathias, Simão

1991

Mendonça, H. B. M. 1912

Mors, Walter Baptist 1997

Peckolt, Oswaldo 1995

Peckolt, Theodoro

Peckolt, Theodoro

Peckolt, Theodoro 1868

Peckolt, Theodoro 1911

Museu Nacional 1874

Museu Nacional 1875

Rheinboldt, Heinreich 1994

Santos, Nadja

Paraense dos 2002

Santos, Nadja Paraense dos; Alencastro, Ricardo Bicca de; Pinto, Angelo da Cunha set. 1999

Santos, Nadja Paraense dos; Pinto, Angelo da Cunha; Alencastro, Ricardo Bicca de 1998

Santos Filho, Licurgo de Castro 1991

Schwartzman, Simon 1979

Silva, Rodolpho Albino

Dias da 1928
Evolução da química no Brasil. In: Ferri, Mário Guimarães; Motoyama, Shozo (coord.) História das Ciências no Brasil. São Paulo: EPU/Edusp.

Necrológio.

Revista Agrícola do Rio de Janeiro.

Natural Products research in Brazil, looking at the origins.

Ciencia e Cultura, Journal of the Brazilian association for advancement of science, v. 49 , n. 5/6, set.-dez., p. 310-4.

Entrevista particular.

6.11.1995. (Mimeogr.)

História das plantas medicinais e úteis do Brasil (1888-1914). 8 v. Rio de Janeiro: Laemmert \& Cia. v. 1 (1888), v. 2 (1889), v. 3 (1890), v. 4 (1891), v. 5 (1893), v. 6 (1896), v. 7 (1899), v. 8 (1914).

História das plantas alimentares e de gozo do Brasil. Rio de Janeiro: Laemmert \& Cia. 5 v. (1871-84), v. 1 (1871), v. 2 (1874), v. 3 (1877), v. 4 (1882) e v. 5 (1884).

Análises da matéria médica brasileira. Rio de Janeiro: Laemmert \& Cia. Análises realizadas e que acompanhavam o material da Exposição de 1868. 108p.

Biografia (Mimeogr.)

Relatório do Museu Nacional.

Rio de Janeiro: Tipografia da Gazeta Jurídica.

Relatório do Museu Nacional.

Rio de Janeiro: Tipografia da Gazeta Jurídica.

A química no Brasil. In: Azevedo, Fernando de (coord.) As ciências no Brasil. 2. ed. v. 2. Rio de Janeiro: Ed. UFRJ.

Theodoro Peckolt, farmacêutico e naturalista do Brasil Imperial.

Tese de doutoramento, Engenharia de Produção, Coppe/UFRJ,

Rio de Janeiro. (Mimeogr.)

A participação brasileira nas exposições nacionais do século XIX: a contribuição de Theodoro Peckolt. In: VII SEMINÁRIO NACIONAL DE HISTÓRIA DAS CIÊNCIAS, São Paulo. Anais... p. 365-8.

Theodoro Peckolt, farmacêutico do Brasil Imperial. Química Nova, v. 21, n. 5, p. 666-70.

História Geral da Medicina Brasileira.

2. ed., 2 v. São Paulo: Hucitec/Edusp.

Formação da comunidade científica no Brasil.

São Paulo: Ed. Nacional, Rio de Janeiro: Finep.

Farmacopéia Brasileira.

São Paulo: Ed. Nacional. 


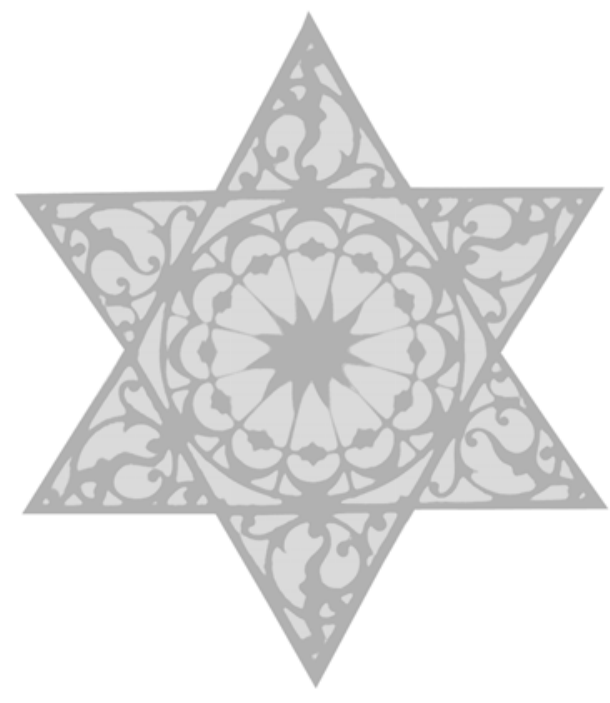

